\title{
Neurological complications of anti-PD-1 antibodies: shall we be more concerned?
}

\author{
Kyrillus S. Shohdy ${ }^{1}$, Omar Abdel-Rahman ${ }^{2}$ \\ ${ }^{1}$ Clinical Oncology Department, Kasr Alainy School of Medicine, Cairo University, Cairo, Egypt; ${ }^{2}$ Clinical Oncology Department, Faculty of \\ medicine, Ain Shams University, Cairo, Egypt \\ Correspondence to: Omar Abdel-Rahman. Clinical Oncology Department, Faculty of medicine, Ain Shams University, Cairo, Egypt. \\ Email: omar.abdelrhman@med.asu.edu.eg. \\ Comment on: Kao JC, Liao B, Markovic SN, et al. Neurological Complications Associated With Anti-Programmed Death 1 (PD-1) Antibodies. JAMA \\ Neurol 2017;74:1216-22.
}

Submitted Jan 26, 2018. Accepted for publication Feb 02, 2018.

doi: 10.21037/tcr.2018.02.04

View this article at: http://dx.doi.org/10.21037/tcr.2018.02.04

Immune checkpoint inhibitors (ICIs) are monoclonal antibodies that target receptors expressed on surface of T-lymphocytes and tumor cells, those receptors such as programmed death receptor-1 (PD-1), and the programmed death-ligand 1 (PD-L1) mediate an immunosuppressive state characterized by $\mathrm{T}$ cell anergy that enables institution of tumorigenesis. ICIs boost the effector immune cells to get rid of tumor cells efficiently. A wide-range spectrum of immune-related adverse effects (ir-AEs) was expected to emerge with the increasing use of those agents. Mechanisms of those ir-AEs are not clear, it was thought to be due to production of antibodies from activated B cells or macrophage-mediated toxicity, in addition to the fact that ICIs unleash the self-reactive T cells (1).

Most of the ir-AEs occur at very low incidence in clinical trials with exception of endocrine dysfunctions and gastrointestinal adverse effects (2). Since targeting the first immune checkpoint receptor, CTLA-4, the neurologic adverse effects (nAEs) emerged as a real concern. One meta-analysis of 59 clinical trials (including 9,208 patients), has found that the overall incidence of nAEs reaching $3.8 \%$ with anti-CTLA4 antibodies, $6.1 \%$ with anti-PD1 antibodies, and $12.0 \%$ with the combination of both (3).

Neurologic complications of ICIs constitute heterogeneous constellations of adverse effects that are usually not properly characterized in large meta-analyses of clinical trials. For instance, one meta-analysis of safety of PD-1/PD-L1 inhibitors compared to chemotherapy has collected data on 12 clinically relevant symptoms. The only reported nAE was sensory neuropathy that was found significantly lower in the PD-1/PD-L1 inhibitor group compared with the chemotherapy group $(1.2 \%$ versus $8.6 \%$; $\mathrm{RR}=0.16)$ (4). Looking into the increasing rate of approvals of ICIs, the real-world clinical data became readily available for further assessment of the safety and efficacy of those drugs. Scrutinizing the evidence on the pattern and severity of neurologic complications with each ICIs and each tumor histology is required due to the associated treatment-related mortality (like the case with pneumonitis) (5).

Kao et al., have published in $7 A M A$ Neurology, a retrospective cohort study representing one of the largest real-world experience on neurologic complications of antiPD-1 antibodies (6). The study focused on anti-PD-1 agents (pembrolizumab or nivolumab) to determine the frequency and severity of nAEs. The study was meant to be a real-world experience through including patients received those agents after their approval from US Food and Drug Administration (FDA). The study retrospectively reviewed 347 patients (59\% received pembrolizumab and $41 \%$ received nivolumab). The treatment-related neurological complications have occurred in ten patients in this cohort. This low frequency of $2.8 \%$ was really reassuring. Most of the patients were elderly (median age of 71 years) and has advanced melanoma or lung cancer. Previous history of autoimmune or neurologic disease was evident in none. Seven of those events occurred with pembrolizumab. Neuropathy and myopathy were the most common nAEs. Co-incident ir-AEs occurred in five patients mainly hypothyroidism and colitis. The study did not find 
Table 1 Characteristics of the retrospective studies on neurologic complications of immune checkpoint inhibitors

\begin{tabular}{lllllll}
\hline Study & Sample & Type of cancer & Treatment & nAEs, n (\%) & Most common AE & Outcome \\
\hline Kao et al., 2017 (6) & 347 & Variable & Anti-PD1 & 10 (2.9) & $\begin{array}{l}\text { Neuropathy [4]; } \\
\text { myopathy [2] }\end{array}$ & Resolved [9]; death [1] \\
Spain et al., 2017 (8) & 352 & Melanoma & $\begin{array}{l}\text { Anti-CTLA-4 and/or 10 (2.8) } \\
\text { anti-PD-1 }\end{array}$ & $\begin{array}{l}\text { Neuropathy [6]; aseptic } \\
\text { meningitis [3] }\end{array}$ & $\begin{array}{l}\text { Resolved [8]; ongoing } \\
\text { symptoms [2] }\end{array}$ \\
Zimmer et al., 2016 (7) 496 & Melanoma & Anti-PD-1 & 16 (3.2) & Varied neuropathy [9]; & Resolved [10]; not improved \\
& & & & seizures [2] & (6 including one death) \\
\hline
\end{tabular}

nAEs, neurologic adverse effects; AE, adverse effect.

any clear pattern of nAEs, the number of treatment cycles to onset of nAEs was variable (range, 1-20 cycles) and the median time from therapy initiation to maximum symptom severity ranged from 1 day to more than 3 months. What is interesting in this study is the detailed description of every neurologic complication, sometimes with confirmation of the diagnosis with electromyography (EMG), magnetic resonance imaging (MRI) and tissue biopsy. The diagnosis of $\mathrm{nAE}$ is cumbersome, as the presentation might be non-specific such as, headache, dizziness, asthenia, and lethargy (7). On histopathological examination, the two cases of myopathy showed muscle fiber necrosis and the sural nerve biopsy from one patient with severe subacute asymmetric neuropathy revealed necrotizing vasculitis. Although the authors did not report the grade of nAEs based on common terminology criteria for adverse events (CTCAE), they reported the modified Rankin Scale (mRS) score. This scale ranges from 0 (no symptoms) to 6 (death). In this cohort, the median $\mathrm{mRS}$ was 2.5 indicating mild to moderate disability. This score might be of value in assessing nAEs in clinical trial setting instead of the conventional CTCAE. All patients discontinued treatment and received immunosuppressive agents namely, corticosteroids (7 patients), IVIG (3 patients) and plasma exchange (1 patient). Only one patient succumbed to severe necrotizing myopathy. Other severe nAEs such as encephalitis and aseptic meningitis were not seen in this cohort.

Of paramount importance, the authors tried to investigate the pathophysiology of those immune-related events, most of the serum connective tissue markers and autoimmune panels were negative except one patient with necrotizing myopathy who was positive for anti-PM/Scl antibodies (these antibodies are associated with polymyositis and systemic scleroderma overlap syndromes). This patient died and was refractory to corticosteroids and three sessions of plasmapheresis. Inflammatory findings were evident on imaging and mixed $\mathrm{B}$ and $\mathrm{T}$ cells infiltrate was seen in biopsy from patients with polyneuropathy.

The results of this study were consistent with a previous retrospective analysis of 496 melanoma patients receiving anti-PD-1 antibodies (see Table 1). Of this cohort, 16 nAEs were reported (3.2\%), most of them were grade 1-2 and resolved spontaneously or with corticosteroids (7). It is worth noting that several case reports published individually documenting nAEs of ICIs might give false impression of higher incidence and severity of this category of complications. In systemic review of 191 publications (reporting on 251 cases), the incidence of nAEs was 9.6\%, however, most cases were with ipilimumab (anti-CTLA-4 antibody). This might be due to including only reports before August 2015 (9).

Another point of debate is the proper algorithm of treatment. In most occasions, corticosteroids are the first choice (10). It is still not clear what should be the next step for steroids-resistant cases. Further research on pathophysiology of these events might help in proper characterization of the sequence of treatment.

\section{Acknowledgments}

Funding: None.

\section{Footnote}

Provenance and Peer Review: This article was commissioned and reviewed by the Section Editor Xian-Xin Qiu (Shanghai Proton and Heavy Ion Center (SPHIC), a.k.a. the Proton and Heavy Ion Center of Fudan University Shanghai Cancer Center (FUSCC), Shanghai, China).

Conflicts of Interest: Both authors have completed the ICMJE uniform disclosure form (available at http://dx.doi. org/10.21037/tcr.2018.02.04). The authors have no conflicts of interest to declare. 
Ethical Statement: The authors are accountable for all aspects of the work in ensuring that questions related to the accuracy or integrity of any part of the work are appropriately investigated and resolved.

Open Access Statement: This is an Open Access article distributed in accordance with the Creative Commons Attribution-NonCommercial-NoDerivs 4.0 International License (CC BY-NC-ND 4.0), which permits the noncommercial replication and distribution of the article with the strict proviso that no changes or edits are made and the original work is properly cited (including links to both the formal publication through the relevant DOI and the license). See: https://creativecommons.org/licenses/by-nc-nd/4.0/.

\section{References}

1. Pardoll DM. The blockade of immune checkpoints in cancer immunotherapy. Nat Rev Cancer 2012;12:252-64.

2. Khoja L, Day D, Wei-Wu Chen T, et al. Tumour- and class-specific patterns of immune-related adverse events of immune checkpoint inhibitors: A systematic review. Ann Oncol 2017;28:2377-85.

3. Cuzzubbo S, Javeri F, Tissier M, et al. ScienceDirect Neurological adverse events associated with immune checkpoint inhibitors : Review of the literature. Eur J Cancer 2017;73:1-8.

Cite this article as: Shohdy KS, Abdel-Rahman O. Neurological complications of anti-PD-1 antibodies: shall we be more concerned? Transl Cancer Res 2018;7(Suppl 4):S436-S438. doi: 10.21037/tcr.2018.02.04
4. Nishijima TF, Shachar SS, Nyrop KA, et al. Safety and Tolerability of PD-1-/PD-L1 Inhibitors Compared with Chemotherapy in Patients with Advanced Cancer: A MetaAnalysis. Oncologist 2017;22:470-9.

5. Shohdy KS, Abdel-Rahman O. Risk of pneumonitis with different immune checkpoint inhibitors in NSCLC. Ann Transl Med 2017;5:365.

6. Kao JC, Liao B, Markovic SN, et al. Neurological complications associated with anti-programmed death 1 (PD-1) antibodies. JAMA Neurol 2017;74:1216-22.

7. Zimmer L, Goldinger SM, Hofmann L, et al. Neurological, respiratory, musculoskeletal, cardiac and ocular side-effects of anti-PD-1 therapy. Eur J Cancer 2016;60:210-25.

8. Spain L, Walls G, Julve M, et al. Neurotoxicity from immune-checkpoint inhibition in the treatment of melanoma: a single centre experience and review of the literature. Ann Oncol 2017;28:377-85.

9. Abdel-Wahab N, Shah M, Suarez-Almazor ME. Adverse Events Associated with Immune Checkpoint Blockade in Patients with Cancer: A Systematic Review of Case Reports. PLoS One 2016;11:e0160221.

10. Eltobgy M, Oweira H, Petrausch U, et al. Immune-related neurological toxicities among solid tumor patients treated with immune checkpoint inhibitors: a systematic review. Expert Rev Neurother 2017;17:725-36. 